\title{
Pre-lesson assignments and formative assessment strategies with interactive invention instruction on low achievers in physics
}

\author{
Edidiong Enyeneokpon Ukoh ${ }^{\mathrm{a}}{ }^{*}$, Sunday Adeyemi Onifade ${ }^{\mathrm{b}}$ \\ Department of Science and Technology Education, University of Ibadan. Oduduwa Road, Ibadan, Nigeria \\ a ee.ukoh@ui.edu.ng, b nsiadiaha@yahoo.com \\ * Corresponding Author.
}

Received: 1 November 2020; Revised: 25 March 2020; Accepted: 31 March 2020

\begin{abstract}
This study examined the impacts of Interactive-Invention Instruction with PreLesson Assignments (PLA) and Weekly Formative Tests Assessment Strategies (WFTAS) on students with low achievement in Physics in Ibadan, Nigeria. Pre-test post-test quasiexperimental research design and ninety Senior Secondary II students participated in the study. Two experimental groups and control were taught using Interactive-invention instruction, in addition, experimental group (1) was exposed to PLA while group (2) was exposed to WFTAS but the control group was only taught with interactive-invention instruction. Physics Achievement Test $(r=0.89)$ and three teachers guides were instruments used while analysis of covariance (ANCOVA) was used to analyse the data. The treatments had significant main effect on low achieving students' achievements in physics $(F(2,75)=9.205 ; p<0.05$, partial $\eta 2=0.197)$. Low achieving students exposed to the treatments obtained a higher post-test mean score of 14.10 for PLA, 16.02 for WFTAS, than those exposed to Interactive-invention instruction only 11.47. It was therefore concluded that the pre-lesson assignments and weekly formative tests assessment strategies improved the performance of low achieving students in physics. It was recommended that teachers identify students with low achievement early and inter-twine their chosen instructional strategies with Pre-Lesson Assignment and Weekly Formative Test Assignment.

Keywords: pre-lesson assignments; students with low achievement in physics; weekly formative tests assessment strategies
\end{abstract}

How to Cite: Ukoh, E. E., \& Onifade, S. A. (2020). Pre-lesson assignments and formative assessment strategies with interactive invention instruction on low achievers in physics. Momentum: Physics Education Journal, 4(1), 49-56. https://doi.org/10.21067/mpej.v4i1.3846

\section{Introduction}

Physics is a science subject that lays foundation for a high reasoning and coping ability in the science and technology related courses in the higher institutions. However, the subject remains one of the most perceived difficult subjects in the school curriculum according to the Nigeria Educational Research and Development Council (NERDC) (Isola, 2010). In spite of the fact that knowledge and applications of principles of physics are very important in the quest for technological advancement of a nation, students' poor performance in physics has continued to be of great concern to the researchers in the field (Adegoke, 2010; Nwagbo, 2008; Ukoh, 2016). Students' performance in senior secondary school certificate examinations (SSCE) administered by West African Examination Council (WAEC) and the National Examinations Councils (NECO) has continued to deteriorate from year to year, particularly in the areas of science (Akubuiro \& Joshua, 2004).

Okebukola and Jegede (1986) subdivided achievement into three categories: High achievers (top 75\%), Medium achievers (middle 55\%), low achievers (bottom 25\%). From reports, most students studying physics has shown to be in the low achievers category which is very disturbing as the nation desires scientific and technological advancement. This group of students are not well catered for in most normal classes because they may be seen to slow down the pace of work and 
they are seen as extra work for the teacher. So, most a time they are neglected and left to struggle on their own some eventually drop out of the subject. The percentage of students with low achievement in physics needs to be drastically reduced early enough at the senior secondary if the stated development goals in the area of science and technology would be realised. Hence, the need to concentrate more on this category of physics students to increase participation in the subject. There are many factors that could be responsible for the repeated low achievement and Ukoh (2016) classified them as government factors, teacher factors, environmental factors, subject matter factors, school factors, parental factors, peer factors and student factors.

Among these factors, the focus of this study is the student factor. The students' academic engagement time which is the time students put into their studies in reading their books, practicing exercises, doing homework or doing some things directly related to their studies outside the normal classroom should be triggered as there are observations that students are no longer taking their studies seriously. The reading culture is gradually eroding by social media activities and other distractions in the environment. Students being involved in economic activities after school hours like hawking, selling in the markets or shops to sustain the family. By the time they get home at night they are tired and with the poor power supply in the nation, they may not be able to do much academic work. It is noted that most of the students only try to study whenever they know that examination is approaching. These have been seen to have caused setbacks more pronouncedly on the achievement of students with low-achievement in physics.

The physics teacher may not be able to change the situation at home of some of these students but could restructure the mode of instruction to help these category of disadvantaged students. This study made use of interactive-invention instructional strategy which has been reported by Ukoh (2012) and Otaru (2015) to improve student's learning outcomes in physics. Also, the effects of Pre-lesson Assignment and Weekly Formative Tests were also determined. The thinking here is that if the students are aware that the teacher is going to look at or grade the assignment he/she asked them to do and will possibly build upon the knowledge generated from the pre-class engagements they will try as much as possible to get it done before the class to avoid punishment likewise the Weekly Formative Test since they know that these will add up to their final grade in the subject, they may want to prepare for it and put in their best. This is believed to have the possibility of increasing the academic engagement time and knowledge absorption rate of these students, should consequently result in improved performance in the subject.

Interactive-Invention Instructional strategy is a learner-centred instructional strategy that emphasises students' active involvement during instruction. The teacher is expected to provide interesting, captivating and rich instructional resources and activities to create good learning experiences based on the concept to be treated while the students are expected to interact with the teacher, classmates and the instructional resources and in the process invent the knowledge they are meant to learn Ukoh (2012). The knowledge gained here will not be 'my teacher said' rather 'I discovered it'. Students discovering the knowledge foster mastery, retention, subsequence application and innovations.

Assessment according to Black and Wiliam (1998) refers to all those activities undertaken by teachers and by their students in assessing themselves, which provides information to be used as feedback to modify teaching and learning activities. Assessment can be "for learning" and it can also be "of learning". Assessment for learning is a means whereby assessment is used to improve learning. It can also be referred to as the form of assessment used before and during teaching as preassessment technique which is a sort of diagnostic test, example of which is pre-lesson assignment. Such assessment becomes formative assessment as the evidence is actually used to adapt the teaching to meet students' needs. Both Pre-lesson assignments and weekly formative tests are forms of internal assessment because they are set and marked by the school. They both can either be objective or subjective as the preferred tool may have a single correct answer (objective) or more than one way of expressing the correct answer (subjective). However, while weekly formative test is a formal assessment, pre-lesson assignment is an informal type of assessment (Adegoke, 2010). 
It is very essential for teachers to know how well students are progressing and where they are having problem so that they can use the information to make necessary instructional adjustment via activities such as pre-lesson assignments and weekly tests. Effort to solve the problem of low achievement in physics, educators in physics have developed various instructional strategies not only to arouse and sustain interest, but also to develop good practical skills, positively attitude of learners to physics and their performance in the subject, albeit refusing to explore alternative assessment strategies (assessment for learning-"AfL" and Assessment of learning- "AOL") as possible means of eliciting improved achievement and performance is an area of concern.

Meanwhile, it is also important to be able to use reading as a resource to enrich a learner's knowledge and information gathering which can take place when students are engaged in assignments and study after school hours. The information gotten can serve as prior knowledge for students at the beginning of a new lesson. When students do assignments, they get involved in the learning process and are able to participate more actively in the classroom (Salami \& Bamidele, 2009). The essence of using tests and other evaluation instruments during the instructional process is to guide, direct and monitor students' learning and progress towards attainment of course objectives (Alonge, 2004; Hanifah \& Irambona, 2019; Kolawole, 2010). Students assimilate and understand the lesson better when they participate in the creation of knowledge and that makes what they learn "stick" rather than memorization which can be forgotten (Otaru, 2015).

As researchers in the field of assessment consider the cultural shifts that arise from the emergence of a more participatory culture, there will be a need to find new methods of applying assessments to learners (Fadel et al., 2007). Among the strategies that promote a meaningful and durable understanding, knowledge transfer of science concepts and processes are formative kind of assessment (Pellegrino et al., 2001), and Pre-lesson assignment technique (Salami \& Bamidele, 2009) which is seen as a possible solution to helping students who show a general lack of understanding of what physics is and if a student does not understand what physics is, they are unlikely to grasp the relevance of physics to them (Sadowska \& Kamińska, 2010). Salami and Bamidele (2009) on the impact of pre-lesson assignments and guided reading approach on student academic achievement which opined that the problem lies with idleness of students after school, inability to transfer the knowledge acquired to new lessons and poor reading habits. Ovute and Ede (2015) also worked on the effect of Pre-Lesson Assignments on Secondary School Academic Achievement and the result of their findings agreed with the opinion Goldstein and Zentall (1999) who stated that pre-lesson assignment as learning strategy is capable of provoking the learners' curiosity and insights in the subject matter, sharpening their general learning skills and as well enhancing their general academic achievement. Goldstein and Zentall (1999) further recommended the technique as the best in enhancing the reading, writing, spelling and mathematical skills of learners when they are well guided.

Among the above-listed factors, the under-utilization or neglect of both assessment for learning and assessment of learning techniques can be a great militating factor contributing to students' unsteady and low level of performance in physics. Aydeniz and Pabuccu (2011) cited that educators have submitted that formative assessment strategies effectively improve students' learning quality as teachers are able to identify students' misconceptions, make these misconceptions visible to learners, device techniques or strategies based on the feedback he/she receives from students to address their learning needs. It is however believed that formative assessment strategies are effective learning tools because they engage students in the process of learning, the learner is able to monitor his/her own state of understanding, identify his/her weaknesses and strengths, and with the aid of this, the teacher and the peers become aware of learning strategies that can boost his/her performance in subsequent tests and examinations through the conceptual understanding of key scientific concepts and processes.

In the constructivist theory, assessment is viewed as a part of the learning process in which students play a greater role in judging their own progress. This indicates that students are challenged both by the teacher and the peers to attain self-regulation. Erinosho (1988) opined that a person who is informed of his successful performance on a test would begin to develop interest in the 
subject and may continue to explore means of doing well in subsequent tasks. Also test given periodically, as continuous assessment test are supposed to remove the threatening effects of a single summative test which is given at the end of a course of study. (Ajogbeje et al., 2013) however opined that some aspects of Continuous assessment that are very relevant to the teaching-learning outcomes include the frequency of the period of reporting on teacher-learner achievements, effecting immediate feedback of result into the teaching-learning situation and the emphasis that the results of these in-course assessment be combined with those of terminal assessments in deciding the final output of the individual learner.

Self-efficacy being one of the variables in this study was first defined in 1977 by Bandura (1978) as a person's belief in his or her personal ability to succeed in specific situations. (Tenaw, 2013) also called it perceived ability, which also refers to the confidence people have in their abilities for success in a given task. It is the belief which a learner has in his/her ability that triggers him/her to put more effort in attaining higher level of achievement in the subject. Individuals who possess a high degree of self-efficacy are more likely to attempt challenging tasks, to persist longer at them, and to exert more effort in the process. If highly efficacious individuals fail, they attribute the outcome to a lack of effort or an adverse environment. When they succeed, they credit their achievement to their abilities. It is their perception that their abilities caused the achievement that affects the outcome rather than their actual abilities (Tenaw, 2013). Fencl and Scheel (2005) carried out an investigation on the effect of strategies on students' self-efficacy from which he reported that the teaching strategies used for instruction also influence students' self-efficacy either positively or negatively. Students appear to push further in their effort to attain a higher level of achievement in physics when the confidences they have in their capability in the subject get increased. By implication, if a strategy that solidifies the believe a student has in himself mastering physics concepts and principle is used, regardless of how true or not of the belief, the child's performance and reading habit would be influenced.

One other factor that has been reported to have connection with achievement in science as one of the academic areas is the gender factor Gender refers to a socio-cultural construct that connotes the differentiated roles and responsibilities of men and women in a particular society. While little after-school moral expectation may be on the male students, the female counterparts have a heavy burden of economic, moral and social responsibilities which hinder them from having time to study at home, placed on their shoulder. World Health Organization (2011) pointed it out that the inability to cope with problems of living in the society that sees the female as a second citizen provides an avenue for psychological disorders. Nnamani and Oyibe (2016) cited that, in most societies, gender has roles based on the women folk, preventing their participating in, and benefiting from development efforts (UNESCO, 2000). This has created a big psychological alienation or depression in the minds of the female students. As a result, boys dominate Chemistry, Physics, Mathematics and Environmental studies classes while the girls go into reading languages and Arts (Nnamani \& Oyibe, 2016).

\section{Method}

This study adopted a pretest-posttest control group quasi-experimental design, using a $3 \times 2 \times 2$ factorial matrix. The experimental group I was exposed to Interactive-invention instruction and Prelesson assignments, experimental group II was exposed to Interactive-invention instruction and Weekly formative tests assessment strategy while the control group was taught using interactiveinvention instructional strategy only. The moderating effect of gender's after-school engagement and self-efficacy was also determined. Participants and Settings

The population comprised of all SSII Physics students in Ibadan South-West Local Government Area of Oyo state, Nigeria and six secondary school. 90 students (59 males and 31females) with low achievement were selected from a population of 201 physics students (111 high-achieving and 90 low-achieving). Analysis of the pre-test and post-test was only carried out on the mean scores of the 90 identified students with low achievement. The six schools were randomly assigned to the 
treatment conditions and six intact classes were used. The students with low achievement and the high achievement category were taught and exposed to the treatments together not to deviate from the normal classroom set up but test instruments were later sorted out based on the identity number and label of type $A$ and Type $B$ given to each of them prior to use of treatment, e.g. TA ('Type $A^{\prime}$ ) for a student with low achievement or TB('Type B') for a student pre-identified as high achievement (the yardstick for TA and TB undisclosed to the students) and must be written on the top of their PAT answer sheet and questionnaires. They were given pretest of all the evaluative instruments which are the Physics Achievement Test (PAT) and Physics Self-Efficacy Questionnaire (PSQ).

Physics Achievement Test (PAT) was developed to measure the students' performance in some specific physics concepts. The items of the physics achievement test were subjected to face and content validity by presenting copies to experts in physics education. The reliability coefficient of 0.89 was obtained using Kuder-Richardson 20 (K.R. 20) to establish the internal consistency of the 20 items. WFT consist of 4 restricted essay test items designed to test students' ability, state definitions correctly, explain concepts, show relationships between data and use the data to solve quantitative problems. It was administered within the last 20-25 minutes of the last period of each week. However, reliability coefficient of 0.74 was obtained using the Kuder-Richardson (K.R.20) to establish the internal consistency of the surviving 24 test items. Method of Data Analysis. The data collected were analysed using inferential statistics. These include; Analysis of covariance (ANCOVA), estimated marginal mean (EMM) and Bonferroni Post-Hoc Analysis.

\section{Result and Discussion}

Ho1: There is no significant main effect of treatent on the achievement of students with low achievement in physics

Statistic result shows that there was significant main effect of treatment on students' achievement scores in physics concepts $(F(2,75)=9.205 ; p<0.05$, partial $\eta 2=0.197)$. The effect size is $19.7 \%$. This means that there is a significant difference in the mean post-achievement scores of students with low achievement. Thus, hypothesis 1a was rejected. In order to determine the magnitude of the significant main effect across treatment groups, the estimated marginal means of the treatment groups was carried out. Physics students with low achievement in Weekly Formative Tests Assessment Strategy (WFTAS) treatment Group 2 had the highest adjusted post-achievement mean score (16.02), and was followed by Pre-Lesson Assignment Assessment Strategy (PLAAS) treatment Group 1 (14.10), while the Interactive-invention Instructional Strategy(IIIS) control Group had the least adjusted post-achievement mean score (11.47). This order is represented as WFTAS>PLA < IIIS. Post achievement of students exposed to Pre-lesson Assignment Strategy (PLAS) was significantly different from their counterparts exposed to Weekly Formative Tests (WFTS) with both groups taught with interactive-invention Strategy, but significantly different from those exposed to Interactive-Invention Strategy Only in their post-achievement scores. Furthermore, the post-achievement score of students with low achievement taught using pre-lesson assignment assessment strategy was significantly different from those exposed to interactive-invention instructional strategy only. This implies that both Pre-lesson Assignments and Weekly Formative Tests Assessment Strategies were the main sources of the significant differences in treatment.

Ho2: There is no significant main effect of gender on the achievement of students with low achievement in physics

Statistic result showed that there was no significant main effect of gender on the achievement of physics students with low achievement $(F(1,75)=0.652, p>0.05$, partial $\eta 2=0.009)$. Thus, hypothesis $2 a$ was not rejected. This indicated that gender had no significant effect on low achieving students' achievement in physics. 
Ho3: There is no significant main effect of self-efficacy on the achievement of physics students with low achievement in Physics

Statistic result showed that there was no significant main effect of self-efficacy on the achievement of physics students with low achievement $(F(2,75)=1.168, p>0.05$, partial $\eta 2=0.030)$. Hence, hypothesis 3a was not rejected. This implies that self-efficacy had no effect on low-achieving students' achievement in physics.

The purpose of the study was to show the effects of pre-lesson assignments and weekly formative tests on the achievement of students with low achievement in physics. The findings showed that the main effect of treatment was significant on achievement in physics. It showed that students exposed to pre-lesson assignment and weekly formative tests assessment strategy with interactiveinvention instructional strategy were significantly different from those exposed only to interactiveinvention instructional strategy in their post-achievement scores. These findings are in agreement with the findings of (Ovute \& Ede, 2015; Salami \& Bamidele, 2009). The result also revealed that both weekly formative tests and pre-lesson assignment assessment strategies were the main sources of significant differences in treatment. Weekly formative tests strategy had the highest postachievement mean scores compared to the other two study groups.

Weekly formative tests assessment strategy group performed better achievement scores than their counterparts in the interactive-invention instructional strategy group. This was because weekly formative tests assessment strategy enhanced bit by bit deep learning which sustains mental alertness, commitment to conceptual tasks throughout the week and correction of misconceived idea. The strategy also eliminates procrastination of reading and fear or threatening effects of summative test and should be used with any instructional strategy. This support the findings of (Adegoke, 2010; Ajogbeje et al., 2013; Black et al., 2004; Black \& Wiliam, 1998).

Pre-lesson assignment assessment strategy was found to boost readiness for learning and helps develop a strong integration power from their consultation of various sources of information which may be connected to the use of concept questions that arouse curiosity in learners. In the prelesson assignment classes, challenging situations were created for the students and were allowed to interact with the teacher in areas of difficulty which was observed to help the student learn and retain knowledge better and creating time to gain more.

Weekly formative tests were also found to have reduced the wide achievement gaps in the class as grading is no longer on one single test favouring only the advantaged group while the teacher can also produce learning curves for references. Attention and level of understanding of concept in physics of students with low achievement were improved. In weekly formative tests classes, there was a great improvement in students' retention and recalling of covered physics concepts. This category of students is not only able to acquire knowledge but also get it down into their minds. Teachers and students are also enabled to understand their learning goals, compare the present performance level to the desired level. That is why Mikre (2011) and Aydeniz and Pabuccu (2011) advocated the use of this strategy in teaching of chemical concepts to the first year university students in Ethiopia and Nigeria respectively. Therefore, it is not a surprise that this strategy study group had the highest post achievement scores over the other two study groups.

There was also no significant main effect of gender on the achievement of physics students with low achievement. That is gender has no influence on achievement which is buttressed by Otaru (2015) and (Al-Zoubi et al., 2009) but negates the findings of (Okeke, 2007), and (Aina \& Akintunde, 2013) who from their independent studies reported that the effects of gender on learning outcomes swerved to favour boys.

\section{Conclusion}

Based on the findings of this study, Pre-lesson Assignments assessment strategy was found to enhance achievement of students with low achievement in physics over what is attained with interactive-invention strategy only. Weekly formative tests assessment strategy was also found to enhance achievement of the students with low achievement in Physics over what is attained with 
Interactive-invention instructional strategy only. This means that the achievement of students with low achievement in physics was better enhanced when each of the assessment strategies was used with interactive-invention instructional strategy than when only the instructional strategy was used. This category of students with low-achievements in physics is catered for with the use of the assessment strategies as their achievement in physics has been enhanced thereby closing the gap between them and their mates who achieves better. In summary, students who are low performers has shown to be less likely to improve their after-school engagements through pre-lesson assignments in physics ahead of next class, but they were more likely to get their achievement improved taking tests weekly. Finally, even though pre-lesson assignment assessment strategy was less significantly related to achievement of these category of students with low achievement, weekly formative tests was a relatively popular strategy and was significantly related to the achievement of the category of students.

\section{References}

Adegoke, B. A. (2010). Integrating animations, narratives and textual information for improving physics learning. Electronic Journal of Research in Educational Psychology, 8(2), 725-748.

Aina, J. K., \& Akintunde, Z. T. (2013). Analysis of gender performance in physics in colleges of education, Nigeria. Journal of Education and Practice, 4(6), 1-5.

Ajogbeje, O. J., Ojo, A. A., \& Ojo, O. A. (2013). Effect of formative testing with feedback on students' achievement in junior secondary school mathematics in Ondo State Nigeria. International Education Research, 1(2), 8-20.

Akubuiro, I. M., \& Joshua, M. T. (2004). Self-concept, attitude and achievement of secondary school students in science in Southern Cross River State, Nigeria. African Symposium: An On-Line African Educational Research Journal, 4(1).

Al-Zoubi, T., El-Shara, I., \& Al-Salam, M. K. (2009). The scientific reasoning level of students' in the faculty of science in Al-Hussein bin Talal University and its affection of gender, teaching level, and specialization. An-Najah University Journal for Research-Humanities, 23(2), 401-437. https://journals.najah.edu/article/357/

Alonge, M. F. (2004). Measurement and evaluation in education and psychology. Adebayo Printing Nig. Ltd.

Aydeniz, M., \& Pabuccu, A. (2011). Understanding the impact of formative assessment strategies on first year university students' conceptual understanding of chemical concepts. Necatibey Faculty of Education Electronic Journal of Science and Mathematics Education, 5(2), 18-41.

Bandura, A. (1978). Self-efficacy: Toward a unifying theory of behavioral change. Advances in Behaviour Research and Therapy, 1(4), 139-161. https://doi.org/10.1016/01466402(78)90002-4

Black, P., Harrison, C., Lee, C., Marshall, B., \& Wiliam, D. (2004). Working inside the black box: Assessment for learning in the classroom. Phi Delta Kappan, 86(1), 8-21. https://doi.org/10.1177/003172170408600105

Black, P., \& Wiliam, D. (1998). Assessment and classroom learning. Assessment in Education: Principles, Policy \& Practice, 5(1), 7-74. https://doi.org/10.1080/0969595980050102

Erinosho, S. Y. (1988). The effect of formative evaluation on the performance of students in Physics. University of Ibadan.

Fadel, C., Honey, M., \& Pasnik, S. (2007). Assessment in the age of innovation. Education Week, 26(38), 34-40.

Fencl, H., \& Scheel, K. R. (2005). Engaging students: An examination of the effects of teaching strategies on self-efficacy and course climate in a nonmajors physics course. Journal of College Science Teaching, 35(1). 
Goldstein, S., \& Zentall, S. (1999). The importance of homework in your child's education. In Center for Public Education.

Hanifah, M., \& Irambona, A. (2019). Authentic assessment: Evaluation and its application in science learning. Psychology, Evaluation, and Technology in Educational Research, 1(2). https://doi.org/10.33292/petier.v1i2.4

Isola, O. M. (2010). Effects of standardized and improvised instructional materials students' academic achievements in secondary school physics. University of Ibadan.

Kolawole, E. B. (2010). Principles of tests construction and administration (Vol. 18). Bolabay Academic Publishing Consultant.

Mikre, F. (2011). Review Article: The roles of assessment in curriculum practice and enhancement of learning. Ethiopian Journal of Education and Sciences, 5(2). https://doi.org/10.4314/ejesc.v5i2.65376

Nnamani, S. C., \& Oyibe, O. A. (2016). Gender and academic achievement of secondary school students in social studies in Abakaliki urban of Ebonyi State. British Journal of Education, 4(8), 72-83.

Nwagbo, C. (2008). Science, technology and mathematics curriculum development: Focus on problems and prospects of biology curriculum delivery. 49th Annual Conference of Science Teachers' Association of Nigeria (STAN), 77-81.

Okebukola, P. A., \& Jegede, J. O. (1986). The under achieving students in science option on the Etiology of Ailment. Journal of Science Teachers' Association of Nigeria, 22(1), 26-30.

Okeke, E. A. C. (2007). Making science education accessible to all. 23rd Inaugural Lecture.

Otaru, J. A. (2015). Effects of interactive- invention and interactive-problem task experiment instructional strategies on students' achievement and interest in physics in two local govt., areas, Oyo state. University of Ibadan.

Ovute, A. O., \& Ede, M. O. (2015). Effect of pre-lesson assignments on secondary school academic achievement in some selected statistical concepts in economics. Quest Journals: Journal of Research in Humanities and Social Science, 3(2), 45-49.

Pellegrino, J. W., Chudowsky, N., \& Glaser, R. (2001). Knowing what students know: The science and design of educational assessment. National Academy Press.

Sadowska, M., \& Kamińska, A. (2010). Problems in teaching physics in primary and secondary school, as seen by young Polish she-teachers. Proceedings of Selected Papers of the GIREP ICPE-MPTL International Conference. https://www.univ-reims.fr/site/evenement/girep-icpe-mptl-2010reims-international-conference/gallery_files/site/1/90/4401/22908/29476/29897.pdf

Salami, M. O., \& Bamidele, E. F. (2009). Comparative analysis of pre-lesson assignment and guided reading teaching approaches on the performance of students in secondary school Biology in Nigeria. African Journal of Educational Research, 13(1 \& 2), 143-149.

Tenaw, Y. A. (2013). Relationship between self-efficacy, academic achievement and gender in analytical chemistry at Debre Markos College of teacher education. African Journal of Chemical Education, 3(1), 3-28. https://www.ajol.info/index.php/ajce/article/view/84850

Ukoh, E. E. (2012). Effects of problem-based learning and interactive invention instructional strategies on NCE pre-service teachers' achievement in physics concepts and acquisition of science process skills. University of Ibadan.

Ukoh, E. E. (2016). Physics teacher effectiveness and time management. In Issues in Teacher Education in Africa. Gbenga Adewale.

World Health Organization. (2011). WHO Global recommendations on physical activity for health. World Health Organization, United Nations. 